\title{
Evaluation and management of heterotopic ossification in patients with spinal cord injury
}

\author{
K Banovac and F Gonzalez
}

Department of Orthopaedics and Rehabilitation, University of Miami School of Medicine, Miami, Florida, USA

\begin{abstract}
Sixty-three patients with paralysis secondary to spinal cord injury (SCI) were screened for heterotopic ossification (HO) by bone scintigraphy $27 \pm 14$ (mean \pm SD) days after SCI. There were four female and 59 male patients, 36 had paraplegia and 27 tetraplegia. The age of patients was $28 \pm 9$ years. Bone scintigraphy was obtained with a 3 -phase test using $99 \mathrm{~m}-$ technetium labeled diphosphonate, and the positive third phase was used as a criterion for diagnosis of HO. Bone scintigraphy was negative for $\mathrm{HO}$ in 27 patients (14 tetraplegic and 13 paraplegic) and positive in 36 patients (13 tetraplegic and 23 paraplegic). The patients with positive $\mathrm{HO}$ were treated with etidronate, first with an intravenous dose of $300 \mathrm{mg} /$ day for 3 days, and then with an oral dose of $20 \mathrm{mg} / \mathrm{kg} /$ day for 6 months. The follow-up of patients consisted of clinical and radiographic evaluations every 2-4 months. The extent of HO was classified radiographically. In the treated group of patients who completed the entire course of etidronate therapy one patient developed $\mathrm{HO}$, the remaining 28 (97\%) patients had no radiographic evidence of $\mathrm{HO}$ during the follow-up of $10.6 \pm 4.5$ months after initiation of therapy.

Our data indicate that: (a) early $\mathrm{HO}$ can be detected in the asymptomatic patients using bone scintigraphy on the average of 4 weeks ( $27 \pm 14$ days) after SCI and (b) the therapy with etidronate might be effective in the prevention of $\mathrm{HO}$ in majority of patients when the treatment is initiated in an early stage of heterotopic bone formation.
\end{abstract}

Keywords: heterotopic ossification; spinal cord injury; etidronate; bone scintigraphy

\section{Introduction}

Heterotopic ossification (HO) is a common complication after spinal cord injury (SCI) which occurs in paralyzed limbs. The incidence of $\mathrm{HO}$ after SCI is approximately $50 \% ;^{1-4}$ in $10-20 \%$ of these patients, HO develops in a more severe form which usually requires surgical therapy. ${ }^{5,6}$ In other patients with less severe soft tissue ossification, HO may cause variable degrees of functional limitations in affected joints. Because the etiology of $\mathrm{HO}$ is uncertain, it is difficult to design an effective diagnostic or therapeutic protocol in its management. Based on the results obtained from the studies in animals, it seems that in the pathogenesis of $\mathrm{HO}$, certain osteoinductive factors capable of stimulating differentiation of soft tissue mesenchymal cells into bone forming cells play an important role. ${ }^{7-9}$ The osteoinductive and mitogenic activities have been identified in the serum of some patients with spinal cord $^{10,11}$ and brain injury ${ }^{12}$ who are prone to develop $\mathrm{HO}$, but biochemical characteristics and the mechanism of action of these substances are presently unknown.

The most commonly used tests in the diagnosis of $\mathrm{HO}$ are radiography and bone scintigraphy. Although

Correspondence: K Banovac radiographic examination is more specific than bone scintigraphy in the diagnosis of bone pathology, the latter test is more sensitive in the diagnosis of many skeletal diseases including HO. In the early stages of $\mathrm{HO}$ the bone consists mainly of osteoid which is readily detectable by bone scintigraphy and will become positive on radiographic evaluation upon accumulation of more minerals about 2-4 weeks later. ${ }^{13,14}$ The results of these imaging studies are important in the therapy of patients, because etidronate, the most commonly used drug in the therapy of $\mathrm{HO}$ in patients after SCI, has an inhibitory effect on the formation of calcium phosphate crystals. ${ }^{15,16}$ Therefore, several groups of investigators have recommended an initiation of therapy in the earliest possible stages while $\mathrm{HO}$ is predominantly in an unmineralized form..$^{13,14,17-19}$ The use of bone scintigraphy in the diagnosis of $\mathrm{HO}$ has also been suggested in order to detect $\mathrm{HO}$ in the initial stage of its evolution. ${ }^{13,14,20,21}$ In the present study we report an effective management of $\mathrm{HO}$ which was based on the screening of asymptomatic patients by bone scintigraphy, consequently resulting in considerable better prevention of $\mathrm{HO}$ than reported in previous studies where the diagnosis of $\mathrm{HO}$ was based on the radiographic examination. ${ }^{17,19}$ 


\section{Methods}

Patients

We studied a group of 63 nonselected and consecutive patients after SCI. They were divided into two groups based on the results of bone scintigraphy. Positive HO on bone scintigraphy was found in 36 patients $(57 \%)$, negative $\mathrm{HO}$ was found in 27 patients $(43 \%)$. In the group of 36 patients with positive scintigraphic findings, there were 23 patients with paraplegia and 13 with tetraplegia. The degree of impairment was graded by American Spinal Injury Association (ASIA) scale. $^{22}$ The age of patients was $29 \pm 11$ years (mean $\pm \mathrm{SD}$ ), (range: $19-56$ years). In the group with positive scintigraphic $\mathrm{HO}$ findings 25 patients had ASIA impairment score A, seven score $\mathrm{B}$, and four score $\mathrm{C}$. In the group of patients with negative $\mathrm{HO}$ findings on bone scintigraphy, there were 13 patients with paraplegia and 14 with tetraplegia. The age of patients was $25 \pm 7$ years (range: $18-48$ ). There were 17 patients with ASIA impairment score of A, four with score $\mathrm{B}$, and six with score $\mathrm{C}$.

\section{Bone scintigraphy}

Bone scintigraphy was performed by a 3-phase test using $99 \mathrm{~m}$ technetium labeled methylene diphosphonate $(99 \mathrm{mTc}-\mathrm{MDP})$. The test was done $27 \pm 14$ days after SCI (range 10-69) days. At the time of bone scintigraphy all patients were asymptomatic without clinical manifestations of $\mathrm{HO}$ such as swelling of the joints or asymmetric reduction of the range of motion. Bone scintigraphy was performed with the dose of 20 to $25 \mathrm{mCi}$ of $99 \mathrm{mTc}-\mathrm{MDP}$. The positive third phase of the test was used as a criterion for the diagnosis of HO. Those patients with positive bone scintigraphy were evaluated radiographically in order to rule out other bone pathology.

\section{Therapy}

The patients with positive bone scintigraphy were treated with disodium etidronate (Didronel, Proctor \& Gamble Pharmaceuticals, Norwich, NY). The treatment was started with intravenous and continued with oral therapy as described previously. ${ }^{20}$ Briefly, the intravenous dose of $300 \mathrm{mg}$ /day was administered over a period of $3 \mathrm{~h}$ for a total of 3 days. Prior to the intravenous medication all patients were hydrated with normal saline $(250-300 \mathrm{ml})$, and an indwelling catheter was inserted in order to prevent bladder distention. Following the intravenous dose of etidronate the therapy was continued with an oral dose of $20 \mathrm{mg} / \mathrm{kg} /$ day for a period of 6 months. The total oral dose of etidronate did not exceed $1200 \mathrm{mg} /$ day.

Follow up of patients

The group of patients with positive scintigraphic findings of $\mathrm{HO}$ was followed clinically and by radiographic examination of affected joints every 2 to 4 months. The extent of soft tissue ossification was determined radiographically using classification of Garland et al. $^{6}$ The period of follow up was $10.6 \pm 4.5$ months (range: 7-22) after initiation of therapy. The group of patients with negative bone scintigraphy on the screening test was followed for a period of $12.5 \pm 7$ months (range: $6-24$ ).

\section{Results}

In the group of patients with positive bone scintigraphy $49 \%$ had single and $51 \%$ multiple involvement of joints. Table 1 illustrates the incidence of $\mathrm{HO}$ at different sites of localization in the positive group. The soft tissue surrounding the hips was the most frequent localization of $\mathrm{HO}$; in $97 \%$ of patients bone scintigraphy was positive either in one or both hips.

Figure 1 summarizes the results of the therapy. In the group of 36 patients with positive HO scintigraphy, the therapy with etidronate was started at the time of diagnosis, on the average of 4 weeks after SCI. In this group, 29 patients completed a course of 6month therapy, one patient developed HO, the remaining 28 patients $(87 \%)$ had neither clinical nor radiographic evidence of $\mathrm{HO}$ during the follow up of $10.6 \pm 4.5$ months (range: $7-22$ ). In the patient who developed HO, the extent of ossification was minimal

Table 1 Incidence of positive bone scans suggesting heterotopic ossification in patients after spinal cord injury

\begin{tabular}{llcc}
\hline Localization of HO & Number of patients & Incidence (\%) \\
\hline \multirow{2}{*}{ Hip } & unilateral & 17 & 47 \\
\multirow{2}{*}{ Knee } & bilateral & 18 & 50 \\
& unilateral & 2 & 5 \\
Ankle & bilateral & 3 & 8 \\
Shoulder & bilateral & 1 & 3 \\
Wrist & unilateral & 2 & 5 \\
\hline
\end{tabular}

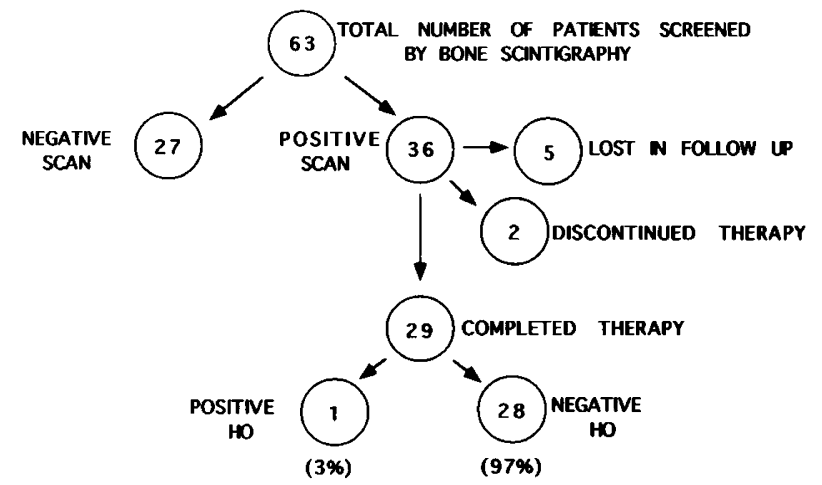

Figure 1 The results of the therapy with etidronate in patients after SCI 
as illustrated in Figure 2; HO in this patient had no effect on the range of hip motion, and it was diagnosed 16 months after therapy with etidronate.

Seven patients with positive bone scintigraphy were excluded from the study because they did not complete the entire experimental protocol. Five patients were lost in follow-up, but had no $\mathrm{HO}$ during the $2.5 \pm 0.8$ months of therapy; two patients were noncompliant and stopped taking medication, both of them developed $\mathrm{HO}$ of grade III after a period of 1 to 2 months.

In the group of 27 patients with negative scintigraphic findings of $\mathrm{HO}$, there was no clinical evidence of $\mathrm{HO}$ during the rehabilitation for a period of approximately 2 months. After completion of their rehabilitation, 15 out of 27 patients were followed in the clinic, three $(20 \%)$ of them developed $\mathrm{HO}$ at time of 4,6 and 18 months after SCI respectively. The degree of $\mathrm{HO}$ was grade I in two patients and grade II in one patient.

\section{Discussion}

Although the pathogenesis of HO is unknown, and the treatment of $\mathrm{HO}$ is symptomatic, clinical experience indicates that the beneficial results in the management of $\mathrm{HO}$ could be obtained when the therapy was started in the early stage of tissue ossification. ${ }^{13,20,23}$ It seems clinically important that the diagnosis and therapy focus on the early stage of $\mathrm{HO}$ evolution, while the immature osteoid contains predominantly amorphous, non-crystalline calcium salts. HO is not detectable on radiographic examination at this stage of formation, and various other tests, such as determination of serum calcium, alkaline phosphatase, hydroxyproline, osteocalcin or osteoinductive activity, have a limited diagnostic value. ${ }^{5,10,14,24,25}$ Several groups of investigators have shown that immature $\mathrm{HO}$ after SCI can be detected by bone scintigraphy. ${ }^{13,14,20}$ Likewise, it was found that in the diagnosis of $\mathrm{HO}$, bone scintigraphy is a more sensitive diagnostic test than radiographic examination and that the test has a high degree of specificity in diagnosis of $\mathrm{HO}^{13,14}$ Freed et al. ${ }^{13}$ reported 17 patients with positive bone scan for $\mathrm{HO}$ and negative radiographic findings who developed $\mathrm{HO}$ 2 to 4 weeks in areas of increased activity on bone scan. Similarly, Orzel and Rudd studied 11 patients to determine the temporal relationship between abnormal bone scan and radiographic soft tissue ossification. The radiographic $\mathrm{HO}$ followed positive bone scan by an average of 15 days. $^{14}$
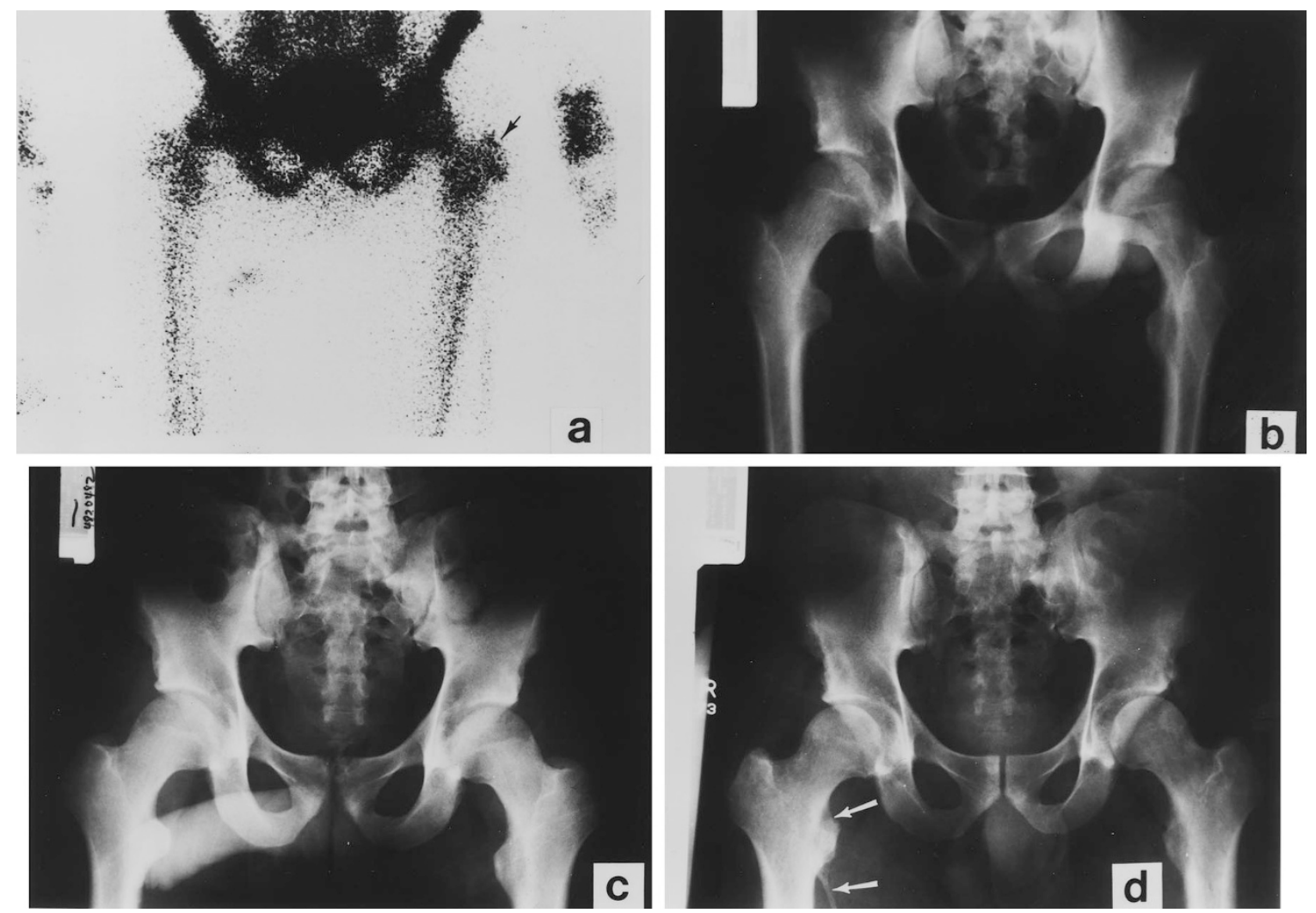

Figure 2 Imaging studies in patient who developed HO after therapy with etidronate. (a) Bone scintigram (the 3rd phase) obtained as screening test for $\mathrm{HO}$ demonstrates bilateral uptake of 99mTc-MDP around hips, more on the right (arrow), indicating $\mathrm{HO}$ in an early stage of development. The radiographic examination at the end of 6-month therapy with etidronate (b) and 4 months later (c) showed no HO. The follow up examination 16 months after therapy (d) showed radiographic grade I $\mathrm{HO}$ in the right thigh (arrows) 
In a previous study we found that the early scintigraphic diagnosis of $\mathrm{HO}$, and subsequent therapy with etidronate, significantly reduced the incidence of $\mathrm{HO}$ after SCI (unpublished data). We were able to prevent $\mathrm{HO}$ in $79 \%$ of the patients who were started on etidronate at the time of scintigraphic diagnosis. In $21 \%$ of the patients etidronate was ineffective and patients developed $\mathrm{HO}$, however, the drug had an inhibitory effect on the extent of heterotopic bone formation when compared to the mass of $\mathrm{HO}$ in the patients who prematurely stopped the therapy. We attributed this incomplete effect of etidronate therapy to delayed diagnosis of HO. Most likely those patients who developed HO already had, at the time of scintigraphic evaluation, a larger mass of immature $\mathrm{HO}$ than the patients who responded to therapy. These findings suggest that in an attempt to diagnose the early stage of $\mathrm{HO}$ formation, the diagnostic procedure should be performed prior to the development of clinical signs and symptoms of local inflammation. Therefore the present study was designed to evaluate the results of the therapy based on the screening of asymptomatic patients. The screening was performed by bone scintigraphy on an average of 4 weeks after injury and resulted in positive findings in $57 \%$ of the patients. This incidence of $\mathrm{HO}$ after SCI was somewhat higher than previously reported by radiographic evaluation ${ }^{1-4}$ because the routine radiographic examination does not always include the evaluation of the entire skeletal system, as is routinely performed by bone scintigraphy. When the treatment was initiated in asymptomatic patients with positive scintigraphic findings of $\mathrm{HO}$, only one out of 29 patients developed a low degree of $\mathrm{HO}$ which was diagnosed after 16 months of follow-up.

Two important aspects of therapy with higher doses of etidronate require discussion, the incidence of side effects and the occurrence of $\mathrm{HO}$ after withdrawal of etidronate. In the present study we used higher doses of etidronate than routinely recommended; the initial intravenous dose of $300 \mathrm{mg} /$ day for 3 days and a 6 month oral dose of $20 \mathrm{mg} / \mathrm{kg} /$ day was significantly higher than commonly used initial dose of $20 \mathrm{mg} / \mathrm{kg} /$ day for 2 weeks followed by $10 \mathrm{mg} / \mathrm{kg} /$ day for 10 weeks. ${ }^{17.19 .26 .27}$ The studies in patients with Paget's disease ${ }^{28,29}$ documented that the administration of $20 \mathrm{mg} / \mathrm{kg} /$ day of etidronate often resulted in development of variable degrees of osteomalacia. Whether the inhibition of mineralization in SCI patients treated with the same doses of etidronate is associated with osteomalacia is unknown. Although it is likely that considerable amount of osteoid develops in the bone of these patients, based on our experience in the present and the previous study, ${ }^{20}$ these were not serious consequences. Some of these patients were followed for a period of 3 years after the therapy and did not develop any complications. Similarly, in a group of SCI patients treated with etidronate $20 \mathrm{mg} /$ $\mathrm{kg}$ /day for 6 months, fractures were not noted during or after the therapy with etidronate (Garland, personal communication). In the therapy of Paget's disease similar doses of etidronate resulted in a significant development of osteoid in pagetic and nonpagetic bone, but these histologic changes were reversible 28,29 and were not associated with a higher incidence of fracture. ${ }^{28,29}$ The experiments in animals confirm these clinical observations. Flora et al. reported that higher doses of etidronate can be administered in patients without fear of a fracture problem; ${ }^{30}$ their results obtained in adult beagle dogs showed that spontaneous bone fractures develop only when the dose of etidronate was approximately 3-5 times the dose of $20 \mathrm{mg} / \mathrm{kg} /$ day used in our study.

Concerning the appearance of $\mathrm{HO}$ after cessation of therapy, it has been shown that after withdrawal of medication there was a rapid increase in the growth of heterotopic bone. ${ }^{17}$ In contrast to these studies where etidronate was given for 2 months, we were not able to document 'rebound' in the appearance of $\mathrm{HO}$ after etidronate therapy. A possible explanation for the differences between these results is the difference in the total dose of etidronate which was higher in our study and could delay the appearance of 'rebound' ossification. Finerman and Stover showed that HO usually appeared in SCI patients on the average of 2 months after therapy. ${ }^{17}$ All patients in our study have been followed for more than 2 months and some of them up to 3 years without any evidence of $\mathrm{HO}$ on radiographic examination. Since etidronate can firmly bind to bone minerals and remain in bound form for an extended period of time ${ }^{31}$ it is probably premature, even after several months, to make conclusions about the 'rebound' effect and long-term results of our therapeutic protocol.

Alternatively we can speculate that in addition to the effect of etidronate on mineralization, high doses of this drug may also cause changes in the function of cells which are involved in de novo formation of heterotopic bone. It has been demonstrated that etidronate can reduce the number of bone forming cells and alter the cell morphology in an experimental model of HO. ${ }^{8,32}$ The cells in the newly formed tissue had an atypical appearance with histologic characteristics of both osteoblasts and osteocytes and were surrounded with atypical extracellular matrix which contained large amount of clear material and poor collagen fibers. Several studies extensively examined the effect of etidronate on osteoclasts, ${ }^{33-35}$ which also showed morphologic and functional changes. In addition to its effect on the bone cells, etidronate has an antiinflammatory effect; ${ }^{19,36-38}$ the mechanism of antiinflammatory action is unknown, but recent data suggest that it may affect the production of interleukin 1 which plays an important role in pathogenesis of experimentally induced HO. ${ }^{39,40}$ Clinical data indicate that etidronate has a dual effect in the treatment of HO. One effect is extracellular, involving mineralization of bone matrix. The other effect is cellular, involving cells responsible for the formation of $\mathrm{HO}$ and inflammatory reaction. A better understanding of 
the role of etidronate in $\mathrm{HO}$, and further investigation of the etiopathogenesis of heterotopic ossification will allow the design of more efficient diagnostic and therapeutic protocols.

In conclusion, the results of this study suggest that our approach in diagnosis and therapy of $\mathrm{HO}$ is more effective than those previously reported. Also, bone scintigraphy performed in asymptomatic patients seems to be a sensitive test for the early diagnosis of HO. Finally, etidronate therapy started at the time of scintigraphic diagnosis may prevent the development of $\mathrm{HO}$ in the majority of patients.

\section{References}

1 Abramson AS. Bone disturbances in injuries to spinal cord and cauda equina (paraplegia): Their prevention by ambulation. $J$ Bone Joint Surg 1947; 30-A: $982-991$.

2 Dejerine A, Ceillier A. Paraosteoarthopathies of paraplegic patients by spinal cord lesion. Clin Ortho Rel Res 1991; 263: $3-12$.

3 Heilburn N, Kuhn WGJ. Erosive bone lesions and soft tissue ossifications associated with spinal cord injuries (paraplegia). Radiology 1947; 48: $579-585$.

4 Liberson M. Soft tissue calcifications in cord lesions. JAMA 1953; 152: 1010 - 1015

5 Garland DE. A clinical perspective on common forms of acquired heterotopic ossification. Clin Ortho Rel Res 1991; 263 $13-29$.

6 Garland DE, Orwin JF. Resection of heterotopic ossification in patients with spinal cord injuries. Arch Phys Med Rehabil 1987; 242: $169-176$

7 Ekelund A, Brosjo O, Nilsson OS. Experimental induction of heteroptopic bone. Clin Ortho Rel Res 1990; 263: 102-112.

8 Plasmans CMT, Kuypers W, Slooff TJH. The effect of ethane-1hydroxy-1,1-diphosphonic acid (EHDF) on matrix induced ectopic bone formation. Clin Ortho Rel Res 1978; 132: 233 - 243.

9 Puzas JE, Miller MD, Rosier RN. Pathologic bone formation. Clin Ortho Rel Res 1988; 245: 269 - 281

10 Kurer MHJ, Khoker MA, Dandona P. Human osteoblast stimulation by sera from paraplegic patients with heterotopic ossification. Paraplegia 1992; 30: $165-168$.

11 Renfree KJ et al. Evaluation of serum osteoblast mitogenic activity in spinal cord and head injury patients with acute heterotopic ossification. Spine 1994; 19: 740-746.

12 Binder SM et al. Evidence for a humoral mechanism for enhanced osteogenesis after head injury. J Bone Joint Surg 1990; 72-A: $1144-1149$.

13 Freed JH, Hahn H, Menter R, Dillon T. The use of three-phase bone scan in the early diagnosis of heterotopic ossification (HO) and in the evaluation of Didronel therapy. Paraplegia 1982; 21: $208-216$.

14 Orzel JA, Rudd TG. Heterotopic bone formation: Clinical, laboratory, and imaging correleation. J Nucl Med 1985; 26: $125-$ 132.

15 Fleisch H, Russell RGG, Francis M. Diphosphonates inhibit hydroxyapatite dissolution in vitro and bone resorption in tissue culture and in vivo. Science 1969; 165: $1262-1265$.

16 Francis MD, Russell RGG, Fleich H. Diphosphonates inhibit formation of calcium phosphate crystals in vitro and pathological calcification in vivo. Science 1969; 165: $1964-1966$.

17 Finerman GAM, Stover SL. Heterotopic ossification following hip replacement or spinal cord injury. Two clinical studies with EHPD. Metab Bone Dis \& Rel Res 1981; 4 and 5: 337-342.
18 Garland DE, Alday B, Venos KG, Vogt JC. Diphosphonate treatment for heterotopic ossification in spinal cord injury patients. Clin Ortho Rel Res 1983; 176: $197-200$.

19 Stover SL, Hahn HR, Miller III JM. Disodium etidronate in the prevention of heterotopic ossification following spinal cord injury (preliminary report). Paraplegia 1976; 14: 146-156.

20 Banovac K, Gonzalez F, Wade N, Bowker JD. Intravenous disodium etidronate therapy in spinal cord injury patients. Paraplegia 1993; 31: 660-666.

21 Citta-Pietrolungo TJ, Alexandar MA, Steg NL. Early detection of heterotopic ossification in young patients with traumatic brain injury. Arch Phys Med Rehabil 1992; 73: 258-262.

22 Ditunno JF Jr, Young W, Donovan WD, Creasey G. The International Standards Booklet for neurological and functional classification of spinal cord injury. Paraplegia 1994; 32: $70-80$.

23 Garland DE. Clinical observations on fractures and heterotopic ossification in the spinal cord and traumatic brain injured populations. Clin Ortho Rel Res 1988; 233: 86-101.

24 Mysiw W, Tan J, Jackson RD. Heterotopic ossification. The utility of osteocalcin in diagnosis and management. Am J Phys Med Rehabil 1993; 72: 184-187.

25 Rossier AB et al. Current facts on para-osteo-arthropathy (POA). Paraplegia 1973; 11: 36-78.

26 Physician's Desk Reference. (Ed.) MEDP Comp., Montvale, NJ, p. 1920,1994

27 Stover SL, Niemann KMW, Miller III JM. Disodium etidronate in the prevention of postoperative recurrence of heterotopic ossification in spinal-cord injury patients. J Bone Joint Surg 1976; 58A: $683-688$.

28 Johnston CC Jr et al. Review of fracture experience during treatment of Paget's disease of bone with etidronate disodium. Clin Orth Rel Res 1983; 172: 186-194.

29 Siris ES et al. Clinical and biochemical effects of EHDP in Paget's disease of bone: Pattern of response to initial treatment and to long-term therapy. Met Bone Dis \& Rel Res 1981; 4 and 5: $301-$ 308 .

30 Flora L et al. The long-term skeletal effects of EHDP in dogs. Metab Bone Dis \& Rel Res 1981; 4 and 5: 289-300.

31 Fleish H. Bisphosphonates. Drugs 1991; 42: 919-944.

$32 \mathrm{Hu} \mathrm{HP}$ et al. The effect of bisphosphonate on induced heterotopic bone. Clin Orth Rel Res 1991; 272: 259-267.

33 Carano A et al. Bisphosphonates directly inhibit the bone resorption activity of isolated avian osteoclasts in vitro. $J$ Clin Invest 1990; 85: $456-461$.

34 Fast DK et al. The effect of diphosphonates on the growth and glycolysis of connective-tissue cells in culture. Biochem J 1978; 172: $97-107$

35 Rowe DJ, Hausman E. The alteration of osteoclast morphology by diphosphonates in bone organ culture. Calcif Tissue Res 1976; 20: $53-60$.

36 Douglas DL et al. Paget's disease: Improvement of spinal cord dysfunction with diphosphonates and calcitonin. Met Bone Dis \& Rel Res 1981; 4 and 5: $327-336$

37 Flora L. Comparative antiinflammatory and bone protective effects of two diphosphonates in adjuvant arthritis. Arth Rheum 1979; 22: 340 - 346

38 Francis MD, Flora L, King WR. The effects of disodium ethane1-hydroxy-1,1-diphosphonate on adjuvant induced arthritis in rats. Calc Tiss Res 1972; 9: 109-121.

39 Aida Y et al. Effects of disodium ethane-1,1-diphosphonate (EHDP) on interleukin 1 production by macrophages. Microbiol Immunol 1986; 30: $1199-1206$.

40 Mahy PR, Urist MR. Experimental heterotopic bone formation induced by bone morphogenic protein and recombinant human interleukin-1b. Clin Ortho Rel Res 1988; 237: 236-244. 